\title{
Reflections on Online Delivered Lessons, During COVID-19 Induced Restrictions, for Students of Informatics in a Vocational Lyceum of Greece
}

\author{
Panagiotis S. Makrygiannis
}

\begin{abstract}
During the pandemic outbreak of COVID-19, coinciding with school year 2019-2020, house confinement measures were taken throughout Greece. Conventional face-toface schooling presented a threat to public health. As a result the Greek Ministry of Education proceeded to suspend school operations for a while and sponsor online lessons of various shapes and forms as a temporary measure soon after. The lessons, hastily designed to address extraordinary conditions and delivered in an ad hoc manner utilizing teachers' personal experiences and preferences to fill a gap created by house confinement, created pressures on existing infrastructures on one hand, and a corpus of diverse experiences, contradicting evidence and on occasion reports on the other. A discussion on that corpus was inevitable and took part originally among teachers of the same school either unofficially or during sessions of the teachers associations of each school. The discussion should and will expand beyond that especially in reference to cases that constitute good practices or where data were collected. To this purpose, this paper presents the case of two theoretical lessons taught at senior high-school students of the Information Applications' Technician specialty in a Vocational Lyceum. The lessons operated surprisingly well, in comparison to similar lessons, concerning student attendance, student engagement level and continuance. Some data were collected with a questionnaire and their processing later informed discussions during reflection plenary sessions of the online class. An attempt is made to explain the divergence from the general case and reflection on results is used to draw conclusions that may benefit further attempts.
\end{abstract}

Index Terms - online education, synchronous lessons, COVID-19, emergency online education, online schooling, student engagement.

\section{INTRODUCTION}

During the pandemic outbreak of COVID-19, coinciding with school year 2019-2020, house confinement measures were taken throughout Greece. Conventional face-to-face schooling presented a threat to public health. As a result the Greek Ministry of Education proceeded to suspend school operations for a while and sponsor online lessons of various shapes and forms as a temporary measure soon after.

The author is a secondary education teacher of Informatics in a Vocational Lyceum (EPAL) of Greece where he also serves as online lessons' liaison for other

Published on December 30, 2020

P. S. Makrygiannis is with the $1^{\text {st }}$ Vocational Lyceum (EPAL) of Perama, Perama 18863 GREECE (e-mail: mgiannis@sch.gr) and also with the Research Laboratory: EATCPS - Electronic Automation, Telematics and Cyber-Physical Systems of the Department of Industrial Design and Production, University of West Attica. teachers that wish to offer such lessons during times of mandatory social distancing. His personal experience from those online lessons, hastily organized and ill-prepared though they were, was positive: both attendance and participation levels were high, engagement of students otherwise indifferent presented an improvement and student commitment to the lessons was remarkable.

That was the case for senior students, of Information Applications' Technician (hereafter IAT) specialty. The lessons were primarily delivered via synchronous online sessions using the Cisco Webex Meetings platform [1], one of the choices provided by the Ministry of Education for this purpose. The platform allows for application sharing and multiple presenters facilitating demonstration of actual activity on the occasional presenter's computer, be it teacher or student [2]. The application also allows for recording [3] but use of the ability was decided against.

The lessons, the same ones examined for admission to tertiary education, were that of "Computer Programming with Python" and "Computer Networks". They went on for four (4) and five (5) weeks accordingly until the Easter vacations and they went on for another three (3) weeks after that due to administrative decisions and a further four (4) weeks after that because of students opting collectively against returning to classes.

Although a first-year introduction level lesson was also taught by the author, in an asynchronous manner, presented a somewhat different picture, the deviation from the general case that the IAT seniors represented was not fully appreciated while on full distant mode. Returning to school based operations made all too obvious that this was not at all commonplace. This realization triggered a small-scale research to explain the reasons behind that deviant behavior towards online lessons.

While the connection of the specialty with Informatics could be expected to be a major contributor to differentiation, some of the data collected pointed out to a number of other major contributors. At the next section of this paper we will present the method used to collect and evaluate these data. The section after that will serve to present some of the semi-quantitative data and the questions formed and hypotheses formulated based on them. The fourth section presents the results of answering the questions and testing the hypotheses with the students themselves and also some unexpected results drown directly from this phase. In the fifth section a reflection is presented on the overall experience and some suggestions for future cases of online delivering of lessons. In the sixth and final section conclusions are drawn, some limitations of the current 
research are presented and further research ideas are suggested.

\section{Method of Study AND Formulation OF Hypotheses}

Tarrow [4] makes a pointthat: a sequence of contributions using different kinds of evidence lead to a clearer and more nuanced understanding (in a specific case of social research he visits). -His reference stands for alterations of proper quantitative and qualitative research but the point is valid for this here educational study also, although it simply makes use of a quantitative tool - that of a questionnaire as a basis for exploration with the intent to inform a purely qualitative process of possible relevant issues.

While a divide between qualitative and quantitative research approaches is generally recognized, some works suggest that one can benefit from the other. As early as 1994 King et al. [5] suggested a way of designing social inquiry, considering what qualitative approaches can gain by keeping in mind the - largely related with quantitative studies - need for rigor. Alas their main suggestion of expanding the number of observations for qualitative studies was not a choice in our case since the number of students in the author's classes was set. Another of their suggestions that of re-specifying hypotheses to allow them to be tested on different units, which has been followed in its results might be presented soon in another article related to online teaching in tertiary education during the same period. Not long after the previous work, Shah \& Corley [6] suggested that it was possible to build better theory by bridging the quantitative-qualitative divide and highlight ground theory as a preferable example of qualitative work.

The study in hand is not ground theory because although it purposely avoids any theoretical preconception in formulating its conclusions, said conclusions do not go far enough to formulate new theory - they just pinpoint weaknesses in existing ones. Even so, and if one is inclined to accept:

a. the questionnaire responses, attendance records and previous classification of students based on real life classes' participation and grades as archival data,

b. the evaluations of participation and engagement during synchronous online sessions as observation and

c. the structured group discussions with participants (as in students) as a proper qualitative method of collecting data while also forming a working theory on the reasons behind the observed phenomena,

the study presents itself as an example of qualitative study of this kind, searching for meaning in how students make sense of their experiences and triangulating the methods used to reach solid conclusions even if they are not enough to form a full theory - beyond a working one. Since no change in the manner of delivery was based on the results of this study, having been concluded simultaneously with the lessons it studied, this is also a non-experimental study[7], minimal teaching adjustments - like allowing more time for student engagement due to raised interest in participation notwithstanding.

It is necessary to point out that this study, on an instance of delivery of synchronous online education, started as an evaluation attempt of two theoretical lessons for senior year
IAT students that the educator delivered online during the unusual circumstances caused by the COVID-19 pandemic in the recently expired school year (2019-2020). The attempt to pinpoint the reasons of the unusually high participation and engagement altered the nature of the endeavor and consequently led to several attempts of modifying and expanding the structure of the study with wavering success. At the end four distinct stages can be recognized:

\section{A. Questionnaire on the online theoretical lessons}

While the number of students in the class (13) was not enough for any serious statistical processing [8] the choice of an online questionnaire was still considered a legitimate choice for a number of reasons:

a. It allowed for the questionnaire to be anonymous thus making sure that responses were not supporting the educators wishes

b. It allowed for submission refusal without fear of repercussions

c. It served to collect data for furthering the formation of hypotheses to be discussed in vivo with the students.

It seems that the second reason was not of relevance after all since most of the students (11) did submit a questionnaire while the rest wanted to, but did not manage to as is proven by their sending of a snapshot of their completed questionnaire by email, admittedly with some delay.

\section{B. Questionnaire on the online laboratory lessons}

Both theoretical lessons have a corresponding but separate laboratory lesson, delivered by a different teacher of Informatics in each case. Discussions with the two colleagues produced a similar level of attendance and also a similar, if somewhat lower, level of engagement. Both provided their approval of using a similar questionnaire for the laboratory lessons.

Surprisingly, only a few (3) students ever attempted to complete the new questionnaire. That led to an extended discussion in the fourth stage of the research where students themselves suggested the reasoning behind their refusal, even revealing voluntarily which ones did and did not complete the second questionnaire. That allowed for some results on online deliverance of laboratory lessons although not based on the relevant questionnaire.

\section{Determination of deviation, Recognizing Key Questions and Formulation of Hypotheses}

On returning to face to face, in class, delivering of lessons a number of things happened at the same time. First, as mentioned already, the deviation of attendance for IAT seniors was made apparent: in almost all classes, the overall attendance of synchronous sessions was under $50 \%$ and only a few of the students attended all or most of the sessions with senior IAT presenting almost the sole exception with another class of seniors in the specialty of electronics being a somewhat close second [9].

That observation made apparent that further investigation was warranted: While the author would gladly accept attribution of most of the results to his own teaching, similar levels of attendance in laboratory lessons excludes that possibility from a major contribution. Furthermore the fact that the same trend did not seem to be present in 
sophomore students of Informatics also excluded the possibility of it being solely attributed to the specialty's affinity with computers.

A number of questions and hypotheses were formed with the help of the quantitative data, which are presented in the next section of this paper, to support further investigation. It was also taken into consideration the fact that all of the students in the IAT seniors' class - presented with the choice - decided on continuing with online synchronous, instead of in class, lessons.

\section{Group Discussion of Findings}

The last stage of this research could be characterized as action research since it took part during the last two sessions of the lessons. The fact that it was a directed discussion focused on specific questions and submitted hypotheses made the discussion resembling more of a Focus Group. During this time students decided to waive their right to privacy in order to elaborate on things they considered important to discuss.

An interesting fact is that very few of the students that were aiming in participating to the examinations for admission in tertiary education followed both those sessions. Since some of the most interesting observations had to do with the attitudes of the rest of the class that was not deemed to weaken the value of the group discussions.

The questions and hypotheses discussed during those two sessions are presented in the next section of this paper while important points from the actual discussion are presented in the following fourth section. These points are attributed to English code-names to protect the privacy of the students even though they themselves gave it up during discussions.

\section{Semi-Quantitative Data, Questions AND HYPOTHESES}

While the answers of the questionnaire were quantifiable and actually quantified they are not proper quantitative data. The sample size is too small to actually use other statistical methods than descriptive; thus the semi-quantitative characterization goes beyond basic. That is not a hindrance in as much as the intended use is merely to unearth dimensions of the observed phenomenon to be dealt with, in the group discussion.

During this session questionnaire data will be presented in pie form. This by no means suggests that this part of the study is capable of producing results on its own as a quantitative research - its sole purpose was to inform the main process of the next step. The choice was made for three reasons, them being brevity of presentation, readiness of recognition of generally positive results and contrast with the results representing reservations on a possible continuance of the online lessons for longer periods.

The questionnaire was delivered electronically (as a Google form) and 11 out of 13 students filed an answer. The remaining (2) students forwarded a completed questionnaire via email with a significant delay, presumably due to technical difficulties. There was a decision not to include the two later delivered answers to the graphs but wherever they alter or considerably strengthen some results, a separate mention to be made.

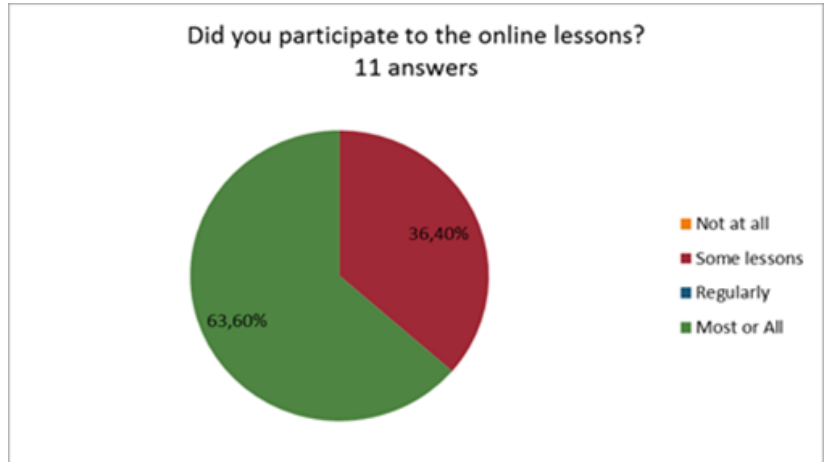

Fig.1 Presumed participation

According to both attendance data and the questionnaire most of the students were very regular in attendance. A few of them underplayed their own: four (4) characterized their attendance with "attended some sessions" while attendance records suggest that only two (2) of them have attended less than two thirds of the lessons. Perhaps they compared their attendance with regular class attendance, were not aware of attendance in other lessons or were influenced in their wording by the fact that their absences were mostly located in the latter sessions. To be noted the fact that both students that did not file their questionnaire with the form had perfect attendance records.

Also to be noted that most of those considered "good students" based on pre-COVID19 data, were not amongst the students with the highest attendance. In fact, of the six highest ranked students according to first semester grading only two ranked in the top half according to session attendance data. Due to that fact, a set of questions was raised:

Q1: Was the change of scenery a reason for the change in attendance patterns? Where there others?

Q2: Was the fact that lessons were originally on a closed cameras setting a reason for heightened participation?

Q3: Did they know that participation was not obligatory for students?

Positive attitudes were recorded towards both lessons by the vast majority of the students, both in general impressions and in familiarity with them.

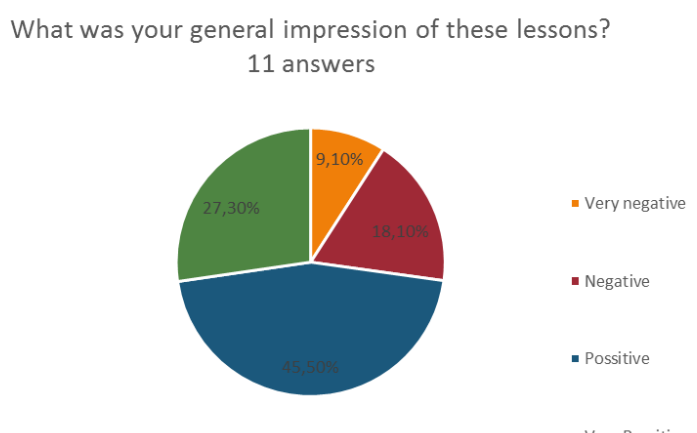

Fig. 2 General Impression from online lessons

That raised another set of questions:

Q4: Did the students enjoy synchronous online learning? Why?

Q5: Did learning occur during synchronous sessions? And 


\section{Q6: What kind of learning was that?}

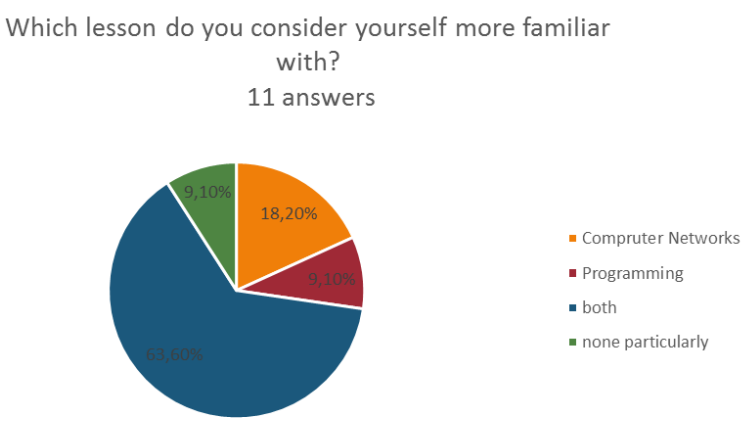

Fig. 3 Familiarity with online lessons

Engagement, estimated by the educator on the basis of either asking or answering relevant questions was higher even than in class engagement.

Again questions were raised by the data:

Q7: Did they study between sessions?

Q8: Why was engagement higher in synchronous online lessons?

More mixed results came from questions on whether they would like the online lessons to continue and whether they thought it would work for longer periods of time. In the first question 6 students answered positively but 5 students answered negatively, and even though the two mail respondents were also strong proponents of continuance it is still an ambivalent result. Similarly, in Fig.4 we can see further ambivalence with both "definitely yes" and "definitely not" receiving one supporter each, "probably not" receiving two supporters and "yes on conditions" seven. Here even the mail respondents were divided: one for probably not and one for yes on conditions! That raised even more questions, especially considering that every single one of them decided to abstain from real life lessons when they were given the chance:

Q9: Why some of the students would not like to see online lessons continue?

Q10: Why did some of them think it would not work for longer periods?

Q11: How does that compute with choosing to abstain from in class lessons?

\section{Do you think online lessons would work for longer periods? \\ 11 answers}

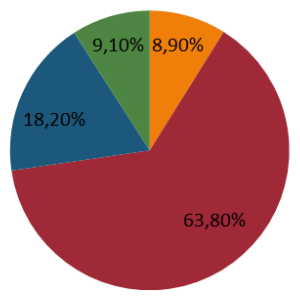

- Definitely Yes

- On Conditions

- Probably Not

- Definitely Not

Fig. 4 Stance on longer periods' viability

With regards to their denial of completing the questionnaire on the laboratory lessons, but also with the fact that all three that answered it stated familiarity with both laboratory lessons:

Q12: Why did they not complete the questionnaire for the laboratory lessons? And

Q13: Do you consider yourselves more familiar with laboratory lessons than theoretical ones?

The questionnaire data created more questions than answers, as is often the case with small number samples. Still, some answers seemed to be able to form and that led to the following hypotheses that were submitted to the students for validation:

H1: A major part of the improved engagement was due to higher engagement of students otherwise indifferent or marginalized.

This hardly needed validation since engagement estimations made it a clear cut conclusion but student perceptions on the matter were deemed important to collect. Furthermore discussion on its validation could, and actually did, present the educator with further explanation.

$\mathrm{H} 2$ : Traffic restrictions and House Confinement changed student perception of what is boring.

To put it in educational terms traffic restrictions and house confinement changed the students' needs making online interactions desirable, even more than face-to-face ones. In the literature it is recognized that some students do rate interactions online to be about the same as those faceto-face [10] but students who prefer face-to-face classes, do so because they enjoy the classroom interactions [11]; in our case such interactions were rendered impossible due to external conditions. The fact of raised student engagement created a reinforcement cycle when recognized by the teacher: the lesson format incorporated a substantial amount of interactions as good online courses are supposed to [12] and thus provided even more desired interaction [13]. Also the fact that urgency forced the ministry of education to allow multiple solutions (big blue button, e-class, webex to mention a few) gave educators the ability to choose tools on the basis of - perceived - instructional needs and student learning outcomes instead of letting them dictate the design of the courses [14].

H3: Closed cameras in the first few sessions made attendance an easier feat than actual corporal presence.

The notion behind the hypotheses was that closed cameras allowed for relaxed participation until a habit of connecting to the session was developed. Combined with the desirability of online interaction, in view of limited availability of live ones, it created a strong habit of attending regardless of the subject of interaction. Easy interaction also allowed some room for reflection, another desirable habit [15] that improved the effectiveness of the course.

H4: The students wanted to continue schooling for the remainder of their last year of it.

The fact that IAT seniors were in the last length of their last year in school was expected to put some pressure towards maintaining contact with their peers. Thus the desirability of the aforementioned interactions was strengthened especially since that particular group of people had developed strong and meaningful relationships prior to traffic restrictions and social distancing. It did not hurt that some of those relationships were of a digital context - group game playing being one of them and joint electronic 
communications ${ }^{1}$ projects another.

H5: The specialty contributed to the attendance through their previous access assurance because of it.

That hypothesis was also considered a safe bet with computer access and possibly ownership taken for granted. Alas, life and research have a tendency to mock strong convictions and certainties, rendering the rejection of a priori theorizing, as suggested by Locke [16] in his introduction to Grounded Theory, good practice.

\section{GRoup Discussion And Results}

Participation in the group discussion was almost as satisfactory as attendance was. Out of 13 students in the senior IAT class $11^{2}$ took part in at least one of the two sessions held at the very last week of the school year in the same manner as the lesson sessions. Most of them participated in both, with three notable exceptions that we will examine further later on. All of the participants took the floor at least once in every session they attended and made several points. The explanatory value of the sessions was beyond all expectations with students presenting valid arguments and honest reasoning for their choices and reactions, voluntarily forfeiting their rights to privacy and individual data protection.

Questions Q1 to Q8 were mostly discussed during the first reflection session while question Q9 to Q13 and hypotheses $\mathrm{H} 1$ to $\mathrm{H} 4$ were mostly discussed during the second. That is not to say that everything about one question or hypothesis came up in the allocated session; on the contrary interconnections were revealed and discussion sometime regressed outside the projected subjects for each session. Still, presentation of results will mostly follow the originally decided pattern in order to facilitate the organization of data collected.

\section{A. Points from the First Session of Discussion/Reflection}

Three students, let us call them Nick, Patrick and Mike gave valuable insights in the ways that the change of scenery caused by mandatory confinement affected attendance patterns. Nick stated that the synchronous sessions "were hard to follow after a couple of weeks of late mornings but it was also great to get into a class, albeit an online one, and meet with people outside your own household". Patrick added that "it helped that they were placed later in the day"'3. Finally Mike made a strong point that he "seamlessly slipped into the online classroom from his room" that was also his base of online learning operations due to him having a personal computer. John, who along with Mary was one of those with a perfect record of attendance, suggested that "this was the only way to attend" while Jim emphasized the point of courtesy. He said

\footnotetext{
${ }^{1}$ A number of IAT seniors maintained joint thematic internet pages and YouTube channels in twos and threes prior to the COVID19 burst. While the fact was expected to hinder online lessons, providing a competitive set of online interactions, it was proven that the faithful adjustment to the situation provided a lot of space -and most importantly time - for online interactions in place of face-to-face ones.

${ }^{2}$ As revealed by their own statements not the same eleven that submitted the questioner from the form.

${ }^{3}$ The lessons were delivered from 11:00 a.m. to 01:00 p.m., originally Tuesdays and Thursdays, but eventually - when general education courses kicked in after Easter - moved to Mondays and Fridays, same time.
}

"I attended every lesson I was invited to. I had to be present" and when asked to whether this had something to do with thinking it obligatory or with the possibility of the system turning into one of obligatory attendance later on, he said he did not think that for a minute and that "it was simply a matter of courtesy".

Closed cameras, that was a practice for the first few lessons and was maintained for the first half hour of all consequent lessons helped people get to lessons as was universally agreed but far less than the educator expected since "after a point appearance and style seemed somewhat irrelevant when confined at home" as one student put it and "we all looked like something a cut dragged from under the bed" to paraphrase another.

Also, all students stated that they knew from the start that participation was not obligatory, with one of them, known here as Jim, stating that "after all we kept coming even after the point that we could not lose the year anymore even if attendance was diligently and officially kept".

Finally there was a sense of "too early to end the school year" - see also results from the Second Session. Bob put it in words best: "I want to know my thing. I might do something else in the end but I need to know what I have studied - need to be able to claim I know how to do this and that". Patrick and John completed the picture completing each other's words: "and name this and that with proper names that show we are not irrelevant or ignorant". Mary, usually not a talkative participant although diligent in class, also added that "we knew it was more difficult for you teachers, keeping your own children at home and preparing materials for the lessons and all" and in another excerpt "you tried hard to deliver and we could tell so it was not an option to let you all hanging".

A further investigation of the reasons behind their continuous attendance led seamlessly to the next few questions inquiring into the pleasantness and effectiveness of the online sessions. They were deemed both pleasant and effective for the most part with a few reservations. Thus, Mary deemed them "very pleasant since there was no classroom noise, we all had time to think and formulate answers" and "very helpful in learning" presumably for the very same reasons. At a different point in time she agreed with Nick that "a camp fire effect came from the talking circle". Bob said that he "noticed things he could have missed in class" probably due to "being in my own space and in a relaxed state". According to him "online lessons are fun". Mike expanded graphically on that same point saying "it was fun to be with the mobile phone in your bed and in a lesson at the same time". On further investigation an interesting bit of information emerged: four of the participants connected solely or mostly from a mobile phone, three did so on occasion and one used a synchronizing app to connect from a personal computer, but communicated via his mobile most of the time - even when in the same room where the personal computer was located.

Still on the matter of learning and clearer understanding, it seems that the classroom holds a special place for, at least, some of the students. In this spirit Jim stated that "although online sessions were fun he prefers school because it helps him better understand things" even though "online sessions were more relaxing". John also found that he both "learned 
some things" and "better understood concepts he was struggling with", but even though "online sessions were very pleasant" they "could not cover everything that physical presence offers ${ }^{4}$ ". Mary agreed that she would not want online sessions to be "the only manner of delivery". Still the point was not unanimous: Bob maintained that for him "online was helpful to learning", that he "learned a lot both in these sessions [the ones of the author's lessons] and in those of the laboratory lessons" and that he feels that "now he can do things with computers he couldn't before". He was mostly alone on this point.

Results on the kind of learning that took place were confusing at the beginning. Students maintained that they "learned a lot", "understood how things worked" and learned "how to do things". Further questioning revealed that they mostly meant the so called "knowledge what" and "knowledge how" categories of knowledge although they did not find the relevant descriptions satisfactory. When SOLO taxonomy [17] was presented to them they found the categories more manageable and they actually succeeded in forming specific outcomes related to programming and digital communications concepts and properly positioning them in the five stages. A summation yielded a few examples of uni-structural thinking, far more of multistructural and relational and, to the educator's absolute delight, a few of extended abstract thinking. A separate paper on the learning outcomes - perceived and measured and the level they coincide - of the two lessons and their comparison is being prepared. For now it suffices to say that a variety of learning outcomes distributed in all categories were observed by teacher and students alike with only minor misconceptions.

With all that learning reported the question whether they studied between sessions came naturally. As expected, here results became mixed. A number of students reported minimal engagement with the material outside the actual sessions. Jim, Mike, Patrick, Terry and Mark, all were in this category offering varying reasons, and sometime, excuses for their practice. That was also to be expected since the group was by no means homogenous: Jim was a student with some learning difficulties, Mike and Patrick belonged to the group of previously indifferent but active in the online lessons students and Terry and Mark were amongst the highest scoring students in written tests and other evaluation activities. Patrick's reason of using his father's office computer during the sessions, since his own collapsed, was mentioned already and gave some credence to his inability to study since reading the book was never one of his strong suits. Accordingly Jim and Mike's excuse of not having a computer in the first place, socking though it was, meant that their only choice to test code was a couple of compilers/ interpreters for python that run on mobiles thus limiting the time one could dedicate in using them to what a mobile user could dedicate to a single application take reading from and writing to mobile phones difficulty into account. Mark used

\footnotetext{
${ }^{4}$ It must be noted here that all specialty lessons from all specialties in Informatics are considered better taught in a laboratory and that is a provision kept, to the best of our ability, in the $1^{\text {st }}$ EPAL of Perama and its supporting $7^{\text {th }}$ Laboratory Center. Thus it is not uncommon even for theoretical lessons to explain concepts via demonstration of real life operations and to a lesser degree through simulations from a number of programs installed in the computer labs' computers.
}

his participation to the tertiary education admission examinations as an - improbable - excuse. His reading was "organized around his own pace and needs" or rather that of his exam tutors. And finally Terry claimed personal problems, a plausible excuse taken into account that he decided against taking the same examinations although he tied in the first place in any and all evaluation exercises along with John.

What was far more interesting was the discussion on the reasons for the elevated engagement observed. In the words of Nick, usual suspects for class noise could not talk to each other, via the platform, as easily since "it is not polite to talk nonsense in the same channel others try to use for serious communication". Mike thought it more rude to "totally interrupt the lesson for a joke or a comment" while Patrick, in a practical note, added that "while a teacher might give a second thought removing someone from the class, in the synchronous session could simply mute him temporarily, not to mention kicking him out of the session". Jim added that "talking over someone else is simply bad manners". When it was pointed out to them, by Mary no less, that in class also one could find difficult to follow the lesson due to "noise" Mike answered that this was perhaps the case but during online sessions "it was more obvious", as was "each other's turn" which reminded the teacher of discussions about the difference of one inflicting harm to somebody and merely accepting the possibility of someone being harmed due to one's own actions later. This is also the part of the conversation that Mary made her point on the helpfulness of the talking circle.

No matter why and how justifiably did the usual culprits feel they could not act their regular way, the connection to their elevated engagement was not obvious to the educator and he contributed that to the discussion. Not the least because some of the people with elevated engagement were not part of this group. Further explanations included that "while in session and not talking to each other or making fun of others certain things popped up and stole their interest" (Nick), "being relaxed and in his own space gave him a push" (Bob), "it was easier to express an opinion during the session" and "it felt safe to express oneself" (Mary) and "talking about the subject was the only way to actually be present" (Mike). Patrick actually had a most improbable explanation "well, trying to beat the others and offer the correct answer first, even in a lesson, seems quite like a game when online, doesn't it?" he offered.

\section{B. Points from the Second Session of Discussion/ Reflection}

The second session started with a discussion of the reasons some students seemed not wanting to see online questions to continue. Of the five students that answered they did not wish for the online sessions to continue four voluntarily revealed themselves and gave their reasoning Mary reiterated that "while she believes she learned from the online sessions and expressed herself more freely while online" she preferred face-to-face interactions for learning. In the same length Bob stated that he "learns better at school and thinks [online learning] would not have worked so well if we did not have a relationship from the regular lessons". John also repeated that "it was not like physical presence in 
a class" and agreed it "worked better because of all the time we spent together in face-to-face lessons". Finally Patrick stated that both his answer to that question and the next about whether online learning could work for a longer period of time were framed by a vision of "school totally online" that he considered a nightmare. Two more students, Jim and Terry volunteered that had they thought that this was where the questions were driving at they would have answered similarly.

When it was pointed out that all of them opted to stay away from school and that might present a contradiction reasoning was woven that did not belong to any of the students involved but rather was collectively formed of four points:

a. the COVID19 outburst is not normal conditions so they had to take it into account (safety first argument)

b. by 'longer periods of time' they understood yearlong sessions that they do not condone (no to totally online schooling argument),

c. attendance actually dropped the period after they could return to school (it actually didn't work as well argument),

d. should the conditions of pandemic persist, other measures should be taken for schooling (this was a patch argument).

A couple of the high attendance students added that they had heard from teachers that we were opposed to using cameras in classroom and so they were worried that had they chosen to return to face-to-face lessons they "would deprive their peers of online sessions". While the author entertains doubts on the centrality of this particular statement in their reasoning, it remains a valid argument and the students in question deserve the benefit of the doubt.

The next set of question held no originality in the students answers. All three students that answered the questionnaire for the laboratory lessons were present, identified themselves and stated that their answer for the laboratories was not divergent with their answer for the theoretical lessons: they felt all four lessons were fit for online delivery in the format of synchronous sessions. Even so, they found parts of the lessons better to be taught face-to-face with special mention to exercises and activities. The rest of the students had identical reasoning for not completing the questionnaire, even though - according to them - they visited it. Phrasing like "labs should not be taught from distance", "we need to put our fingers on it", "hands on the bench" were prevalent to the extent of raising suspicion that they had discussed the subject amongst them or even with some teachers prior to visiting the form. All of them denied such occurrences and stated that "it is common sense so it is commonly phrased" (Patrick). While such views are common among teachers of the $7^{\text {th }}$ Laboratory Center they are not held with such conviction by teachers of Informatics even when they are considered sensible, at least to a point.

In a similar reaction to the question whether the students considered themselves more familiar with laboratory lessons than theoretical ones the educator/ researcher was faced with a block response. While some of the students adopted a defensive stance in regards of the theoretical lessons under consideration, and taught by the discussion coordinator, a couple of points were unanimously accepted and put forward ${ }^{5}$.

a. Vocational Lyceum (EPAL) students are by nature inclined to laboratory activity and better suited for hands on learning

b. Most of the senior class lessons are specialty and almost all of those pure laboratory or mixed lessons, with only the two examined in national examinations for admission to tertiary education are separated by their respective laboratory ones.

c. All specialty theoretical hours in Informatics are delivered in labs in our schools.

The fact that the first two points represent the author's opinions and the third a reality formed by the commonality of such opinions in the 7th Laboratory Center (7th EK) of Piraeus could put the objectivity of the students position under question, but the forcefulness of their position even against a questioner championed by himself points to a strong view commonly held.

Furthermore three of the students present reminded the discussion coordinator that they were only attending specialty lessons - as holders of a graduation certificate from another school or specialty - which was the case for at least one more among the ones absent and which reinforced all three points made by all of them. I was also reminded by John that I personally insisted on a hands-on and on computer approach to programming while teaching the theoretical lesson.

At this point exegetic hypotheses put forward by the author were presented to the students for validation purposes with mixed results once more. Hypothesis H1 stating that higher engagement of students - otherwise indifferent or marginalized - contributed to the overall improvement was challenged only regarding its phrasing and otherwise summarily accepted. The challenge referred to the fact that all four students in this category did not feel marginalized and wanted to make a point that were not indifferent per se but "not properly serviced by the classroom model on theoretical lessons" (Nick), a point reinforced by the fact that Nick actually decided to participate in the national examinations upon feeling that he could cope with, after only five (5) weeks of online lessons.

Hypothesis $\mathrm{H} 2$, charging traffic restrictions and house confinement with changing student perception of what is boring and thus making online sessions more interesting was received with some reservation but while the discussion moved on was accepted as revelation. Statements like "it filled an otherwise empty day" (Mike), "I started studying what we discussed in order to pass more time" (Nick), "I had missed every single of my co-students by the time the sessions started" (Patrick), "gave me a reason to wake up, make coffee, sometimes even shave" (John), "I was on the net or my mobile communicating anyway but this gave me something to actually do and sometimes even talk about with friends" (Bob), "beats watching the ceiling" (Don) and "it seemed kind of fun, more so than regular classes though I could not tell why before" (Mary) were enthusiastically offered in its defense.

Hypothesis H3 about the closed cameras during the first 
sessions helping jumpstart the process seems to hold some truth but was not holding the important exegetic power originally thought. Already from the previous session it had been obvious that students were ready to go to synchronous sessions regardless. As Patrick put it "by then I was already ready to show my tussled hair to the world for five minutes of meaningful conversation" and Bob added "I would have shown up in pajamas if necessary and no question about it". But of course it held some sway: according to John he liked "to make coffee without being seen" and that is why he "so much appreciated" maintaining the closed cameras policy for the initial half hour of the sessions.

The next hypothesis, H4, that suggested students wanted to continue schooling for the remainder of their last year of it proved to hold strong influence to students' attitudes. Summarily accepted, albeit without much enthusiasm, produced comments such as: "I would have come to school if online was not a choice" (Mary, Patrick and Mike), "I wanted to complete my studies, not be awarded a pity certificate" (John and Bob), "would love a couple more weeks, preferably face-to-face" (Terry), "I will come back for another specialty" (Bob), "I did not come back to school for a moodle" (Dick). It seems that a combination of external conditions and choices made - for example synchronous sessions instead of asynchronous delivery gave the need for actual schooling in seniors an important role in forming their attitudes towards the online sessions. Perhaps Mark and Brian, that were not present in this session, could have offered a contrary opinion.

Finally, hypothesis H5 on the role of specialty in forming the divergence of this class from the general situation proved dubious. The premise behind it was that IAT seniors would have their own equipment, in the form of computers and tablets and smarter smart phones, at home. The premise collapsed far before getting to the final part of the discussion although the idea might actually hold some merit. We have already seen that people did not have computers, or they soon failed or they were too old to support synchronous online sessions - many students connected solely or mainly through smart phones. Even those were not as widespread as expected: three students did not have a smart phone and one had something that was smart in the far past and took some work to support synchronous communications. To further mock certainties discussion still revealed some specialtycentered reinforcing factors in the process, although not the expected ones: Bob said that "alternating the host and presenter roles among the students hold some interest" familiarizing them with the "inner workings of synchronous education", Patrick added that "online meetings is generally good business practice" and Mike added that "the [COVID19] pandemic might make such things more important", while John informed us that "having no available remote access application [he] used webex meetings to help another student repair their computer". Don, who rarely offered something during the reflection sessions made a comment that he also "enjoyed being in charge". So after all there was some professional interest to the process but not that major and certainly the contribution was not due to any previous access assurance.

The falling attendance records of three of the academically stronger students was brought up by other students during this session, opportunity taken by the fact that Terry was absent this time along with Brian and Mark. Due to none of them being present discussion did not expand but it was pointed out by another student that Brian and Mark had the worst attendance records during the online sessions after Carl whose family conditions demanded that he took up a job and almost did not complete the year.

\section{TEACHER REFLECTION AND CONCLUSION}

There is one thing certain about this application of online learning caused by the burst of a pandemic: it was hasty by necessity and found most unprepared. But that fact had its positive side too: the Ministry of Education was obliged to offer multiple choices to teachers that wished to offer online lessons, choices synchronous and asynchronous and on various platforms. That left teachers with a relative freedom to form their own lessons according to their previous experiences and utilize their strengths.

The author tried both asynchronous and synchronous solutions in this context. The synchronous ones had vastly better success than the asynchronous but they were not competing on a level ground: the synchronous ones were addressed to seniors and the asynchronous to first year students. Still, the fact remains that synchronous lessons worked well for senior IAT students; they actually worked better than any other online lesson in the $1^{\text {st }}$ Vocational School of Perama or the $7^{\text {th }}$ Laboratory Center of Piraeus.

There was an initial thought that high participation and engagement level was, to a large extent, explainable by availability of equipment due to the specialty's relevance but that was disproved. It seems though that the specialty did offer some fascination with the technical side albeit a limited one.

It seems more probable that their divergence had to do with the kind of relations developed within the class and maybe with the teachers to some extent. This does not fully explain why the lessons worked that well although it strongly suggests the relevance of the quality of previous face-to-face interactions. What also has exegetic value is the fact their answers during the reflection sessions showed a descent understanding of themselves, empathy to their peers and some understanding of how the world works. It almost seems as if they have collectively achieved what Goleman and Senge call triple focus [18].

It has also been shown that a number of the choices made in the process of designing the lessons in question were right for those specific students: besides the choice of having synchronous sessions, the talking circle practice reigns supreme. The talking circle practice, both in answering questions and offering remarks consists of keeping track of who last answered and who last commented and give the next in the circle a chance to contribute next time. The discussion sessions' commentary seems to suggest that it worked towards freeing some of the potential in the class both setting a turn that was rude to break and making it easy to contribute; taking our time while someone formed an answer or comment seems to have also helped. Interactions were strengthened and boosted in numbers.

Another practice, of letting students alternate as presenters, also brought something to the dynamic. Besides having to have produced something to present it which was 
often a case, even being the one that actually tried everyone else's ideas, suggestions and solutions did something to raise the level of interaction.

Letting students alternate as hosts also worked well. It freed the teacher from some administrative load while at the same time satisfying a mild curiosity about the inner workings of synchronous online learning; not to mention raising the levels of the feelings of ownership of the process.

All four major choices worked in tandem to raise the levels of interaction and ownership of the process. The level of interaction in online courses is often seen as a predictor of students' perceived learning [19] as is the feeling of ownership. Together, perceived learning and ownership created an environment appropriate for learning, by creating a reinforcing loop with participation and engagement with great results for the two lessons' effectiveness. Student satisfaction was expressed through both sustained high attendance levels, with high levels of engagement and the choice of continuing in the same manner for a further five (5) weeks.

\section{APPENDIX}

Normally both the questionnaires and the answers would be appendixes of this paper but their online availability renders such an encumbrance of space unnecessary. Both the questions and the answers in pie form can be found here:

https://docs.google.com/forms/d/e/1FAIpQLSfUIT861ZqrJhDg6 kPKy6k-c8RaemEizr8z7U2MHZmsweNWrQ/viewanalytics and here:

https://docs.google.com/forms/d/e/1FAIpQLSdNHCagdmvZ3N uyoS35m8XAQQ O4r6AX7F2vz7m0xirmvSBhQ/viewanalytics

\section{ACKNOWLEDGMENT}

The author would like to thank fellow informatics teachers L. Psani, and N. Chatzikostandis that allowed him to attempt to gather data for their corresponding laboratory lessons. Also the $7^{\text {th }} \mathrm{EK}$ of Piraeus in general for their positive attitude towards expanding the study over school boarders.

Fellow teachers N. Katsaris, N. Trichas, and D. Kotsifakos freely shared their own experiences and insights on the reflection sessions and the author is indebted to them for this reason.

E.C. Papakitsos labored to make sense of an early version of this paper and offered insights and also questions that helped improve it.

\section{REFERENCES}

[1] Cisco WebEx Meetings, CISCO Inc., Luettavissa. Luettu, 18, 2014 Available: http://www.webex.com/products/web-conferencing.html.

[2] M. Zhu, \& S. Wei (2007). "System and method for application sharing in collaborative setting." U.S. Patent No. 7,203,755. Washington, DC: U.S. Patent and Trademark Office.

[3] M. Zhu, S. Wei, \& A. L. F. Pong, (2007). "On-line conference recording system." U.S. Patent No. 7,213,051. Washington, DC: U.S. Patent and Trademark Office.

[4] S. Tarrow. (2004). Bridging the quantitative-qualitative divide. In $\mathrm{H}$ E. Brady and D. Collier (Eds.) Rethinking social inquiry: Diverse tools, shared standards, 170-180.
[5] G. King, R. O. Keohane, \& S. Verba. Designing social inquiry: Scientific inference in qualitative research. Princeton university press, 1994.

[6] S. K. Shah, \& K. G. Corley. (2006). Building better theory by bridging the quantitative-qualitative divide. Journal of management studies, 43 (8), 1821-1835.

[7] B. Johnson. (2001). Toward a new classification of non-experimental quantitative research. Educational Researcher, 30 (2), 3-13.

[8] J. W. Creswell, (1994). Research design: Qualitative \& quantitative approaches. Thousand Oaks, CA: Sage Publications.

[9] D. Kotsifakos, M. Manis \& S. Tsoukalas, (2019). "Modern Ways of Vocational Lyceum Lesson Support: Application Study on the lesson Structure and Operation of Microcomputers, of Electronics Specialty", in Proc. 11th Conf. Informatics in Education, 2019 - ( CIE 2019) October 11-13, 2019. Available: http://lefkimi.ionio.gr/cie/images/documents19/cie2019 Proc OnLine /new/custom/pdf/3.1\%20CIE2019 660.025 Kotsi_Final_p.pdf

[10] E. I. Allen, \& J. Seaman, (Eds.). Going the Distance: Online Education in the United States, 2011 Sloan Consortium

[11] T. Daymont \& G. Blau. (2008). Student performance in online and traditional sections of an undergraduate management course. Journal of Behavioral and Applied Management, 9 (3), 275-294.

[12] M. Clark-Ibáñez \& L. Scott. (2008). Learning to teach online. Teaching Sociology, 36 (1, Lessons Learned at the 2007 ASA Annual Meetings: Insights from the Teaching-Related Workshops), 34-41.

[13] K. Marshall. (2009). What data-driven instruction should really look like. Teacher Magazine. Available: http://www.nwp.org/cs/public/download/nwp file/12584/

[14] L. P. Kushnir \& K. C. Berry. Inside, Outside, Upside Down: New Directions in Online Teaching and Learning. International Association for the Development of the Information Society, 2014.

[15] A. L. Costa \& B. Kallick. (2000). Getting into the Habit of Reflection. Educational leadership, 57 (7), 60-62.

[16] K. Locke. Grounded Theory in Management Research. Thousand Oaks, CA: Sage, 2001

[17] J. B. Biggs \& K. F. Collis. Evaluating the quality of learning: The SOLO taxonomy (Structure of the Observed Learning Outcome). Academic Press, 2014

[18] D. Goleman \& P. Senge. The Triple Focus: A New Approach to Education. More Than Sound, 2014.

[19] A. P. Rovai \& K. T. Barnum. (2003). On-line Course Effectiveness: An Analysis of Student Interactions and Perceptions of Learning. Journal of Distance Education 18 (1), 57-73.

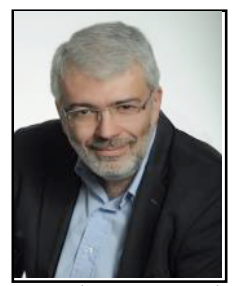

Panagiotis S. Makrygiannis was born in Athens in 1968. He graduated from the Dept. of Informatics, National \& Kapodistrian University of Athens, Greece, in 1995. He holds a European Master in Multimedia \& Audiovisual Business Administration issued by Haute Ecole St. Louis, Brussels, in 2000, and a Master of Education (M.Ed.) in Educational Technology and Development of Human Resources issued by University of Athens in 2010. He also earned a postgraduate diploma in Vocational Guidance and Counseling from Panteion University of Social \& Political Sciences, Athens, Greece, in 2008.

He has 20 years of teaching experience in secondary vocational education and has worked as sessional staff in three tertiary education institutions in Athens, Greece. He has served in positions of scientific, pedagogic and administrational responsibility. He has conducted research for various scientific and professional organizations and coordinated the InterScientific Institute for European Strategy, Analysis and Planning for a number of years (2002-2013), Author, co-author and editor of a number of books on the application of IT in various sectors and also teaching books for students of informatics, has also been a member of Syllabi development committees of the Institute of Educational Policy of Greece for the corresponding lessons. He is currently conducting research on extended blended learning and teaching technologically heavy subjects as part of his $\mathrm{PhD}$ studies with the University of West Attica.

Mr. Makrygiannis is a member of various professional and scientific organizations and served as a member of the Board in several of them. $\mathrm{He}$ is currently member of the Board of the Scientific Association for Technological Education and Training. 